\title{
Animal model of gluten induced enteropathy in mice
}

R Troncone, A Ferguson

\begin{abstract}
The aim of our experiments was to produce a local $\mathbf{T}$ cell mediated immune response to gliadin in the mouse small intestine as a possible animal model of gluten sensitive enteropathy, coeliac disease. BALB/c and BDF $_{1}$ mice were immunised systemically with gliadin in complete Freund's adjuvant. The jejunal mucosa was challenged by feeding a gluten containing diet, and villus and crypt lengths, crypt cell production rate, and intraepithelial lymphocyte counts were determined to assess mucosal cell mediated immunity. In some animals permeability and local immunity were modulated by concurrent intestinal anaphylaxis or a graft versus host reaction. There were no changes in the jejunal mucosa of BALB/c mice fed a gluten containing diet after having been parenterally immunised. When, however, mice were parenterally immunised with gliadin, fed a gluten containing diet, rendered hypersensitive to helminth antigen by infection with the nematode parasite Nippostrongylus brasiliensis, and challenged intravenously to produce intestinal anaphylaxis crypt cell production rate was significantly higher than in ovalbumin immunised controls at 12 days after parasite challenge. Finally, graft versus host reaction was induced in BDF $_{1}$ mice that had been parenterally immunised with gliadin and were on a gluten containing diet. Two weeks later these mice had significantly longer crypts and a higher crypt cell production rate and intraepithelial lymphocyte count than control, unimmunised mice with graft versus host reaction. We conclude that active immunisation with gliadin does not in itself produce intestinal cell mediated immunity to gliadin contained in the diet, or enteropathy. Additional factors, such as those occurring during intestinal anaphylaxis (increased intestinal permeability), or during graft versus host reaction (enhanced antigen presentation), seem to be necessary for the full expression of a jejunal mucosal reaction.
\end{abstract}

Coeliac disease is a permanent condition of gluten intolerance. There is an increasing body of evidence for an immunological aetiology, with local cell mediated immunity thought to be the major cause of the mucosal lesion. ${ }^{1}$ If this hypothesis is correct, and unless specific immunogenetic factors are critical, an animal model should readily be produced by priming the animals to gluten and then challenging them by feeding. Studies in rodents, however, have shown that oral tolerance rather than priming is the usual result of feeding a protein antigen. Under such conditions, mucosal cell mediated immunity is not elicited, ${ }^{2}$ and in this respect gliadin behaves in the same way as other dietary proteins. $^{3}$

In this series of experiments, our aim was to induce mucosal cell mediated immunity to gliadin in mice. Initially we used animals weaned and maintained on a gluten free diet. They were immunised systemically in order to prime for cell mediated immunity to gliadin, and a normal rodent gluten containing diet was used to deliver gluten to the gut of test animals. Indirect evidence of active mucosal cell mediated immunity was sought by measuring villus and crypt lengths and crypt cell production rate and by performing intraepithelial lymphocyte counts.

\section{Methods}

ANIMALS AND DIETS

Female BALB/c mice were used, aged 6 to 10 weeks, unless otherwise stated. They were from a gluten free colony established in 1985 and maintained on a gluten free diet (Special Diet Service, Witham, Essex); only second or later generation mice were used for these experiments. Female BALB/c and $\left(\mathrm{C} 57 \mathrm{BL} 6 / \mathrm{J} \times \mathrm{DBA}_{2}\right) \mathrm{F}_{1}\left(\mathrm{BDF}_{1}\right)$ mice were also used, maintained on a standard rodent diet which contains $2 \cdot 8 \%$ gluten (CRM(X), Labsure, Poole, Dorset). This diet was also used for oral challenge with gliadin. There were six mice in each experimental group.

\section{SYSTEMIC IMMUNISATION}

For systemic immunisation purified gliadin was used (kind gift of $\mathrm{Dr} \mathrm{H}$ Weiser, DFA für Lebensmittelchemie, Garching, Germany). Mice were immunised with $50 \mu \mathrm{g}$ of gliadin in distilled water emulsified in $50 \mu \mathrm{l}$ Freund's complete adjuvant (Bacto-H37 Ra, Difco, West Molesey, Surrey). Control mice were immunised with $100 \mu \mathrm{g}$ ovalbumin (Sigma, Poole, Dorset) in Freund's adjuvant. In most experiments mice were immunised intraperitoneally, but in some experiments intrafootpad and subcutaneous injections were also used.

\section{IMMUNOMODULATION TREATMENTS}

\section{Intestinal anaphylaxis induction}

BALB/c mice were infected by subcutaneous injection of 1000 larvae of Nippostrongylus braziliensis. Ten days later anaphylaxis was induced by the intravenous injection of 400 worm equivalents of Nippostrongylus antigens. Animals were sacrificed 12 days after the induction of anaphylaxis. 
TABLE I Duodenal mucosal architecture of $B A L B / c$ mice weaned on a gluten free diet (GFD) or on a normal gluten containing diet (ND), of ND mice after seven days of GFD, and of GFD mice after one and seven days of $N D$

\begin{tabular}{|c|c|c|c|}
\hline Animal group & $\begin{array}{l}\text { Villus length }(\mu m) \\
(\text { mean }(S D))\end{array}$ & $\begin{array}{l}\text { Crypt length }(\mu \mathrm{m}) \\
(\text { mean }(S D))\end{array}$ & $\begin{array}{l}\text { Crypt cell production } \\
\text { rate (metaphases/crypt/h, } \\
\text { and confidence intervals) }\end{array}$ \\
\hline $\begin{array}{l}\text { GFD weaned mice }(n=6) \\
\text { ND weaned mice }(n=6) \\
\text { ND mice }(n=6) \\
\text { ND mice after } 7 \text { days of } \\
\text { GFD }(n=6)\end{array}$ & $\begin{array}{l}979(52) \\
982(61) \\
881(101) \\
902(71)\end{array}$ & $\begin{array}{l}111(5) \\
107(10) \\
102(7) \\
104(6)\end{array}$ & $\begin{array}{l}6 \cdot 3(5 \cdot 0 \text { to } 7 \cdot 7) \\
5 \cdot 6(4 \cdot 3 \text { to } 7 \cdot 0) \\
4 \cdot 9(3 \cdot 7 \text { to } 6 \cdot 1) \\
4 \cdot 2(2 \cdot 5 \text { to } 5 \cdot 9)\end{array}$ \\
\hline $\begin{array}{l}\text { GFD mice }(n=12) \\
\text { GFD mice after } 1 \text { day of ND } \\
(n=12)\end{array}$ & $\begin{array}{l}854(77) \\
924(174)\end{array}$ & $\begin{array}{l}109(16) \\
116(10)\end{array}$ & $\begin{array}{l}3.0(0.6 \text { to } 5 \cdot 5) \\
6.3(3.2 \text { to } 7 \cdot 2)\end{array}$ \\
\hline $\begin{array}{l}\text { GFD mice after } 7 \text { days of ND } \\
(n=12)\end{array}$ & $841(85)$ & $103(7)$ & $4 \cdot 3(2 \cdot 8$ to $5 \cdot 7)$ \\
\hline
\end{tabular}

In none of these experiments were differences between groups significant.

Graft versus host reaction

A graft versus host reaction was induced by the intraperitoneal injection of $6 \times 10^{7} \mathrm{C} 57 \mathrm{BL} 6 / \mathrm{J}$ spleen cells into $\mathrm{BDF}_{1}$ mice. Spleen cell suspensions were made with RPMI 1640 medium (Flow Laboratories) and the viability as assessed by $2 \%$ Trypan blue exclusion was greater than $85 \%$. For documentation of graft versus host reaction, at the time of their sacrifice 7,10 , and 14 days after the induction of the reaction, animal body and spleen weights were measured and Simonsen's spleen index calculated. ${ }^{4}$

\section{INTESTINAL MORPHOLOGY AND EPITHELIAL CELL} KINETICS

\section{Villi and crypts}

Lengths of villi and crypts, and crypt cell production rates, were measured by the metaphase arrest and microdissection techniques. ${ }^{5}$ All groups of animals were given $7.5 \mathrm{mg}$ colchicine (BDH) per kg bodyweight and killed by cervical dislocation at intervals of 20-120 minutes afterwards to allow accumulation of metaphases in intestinal crypts. Pieces of duodenum were fixed in $75 \%$ ethanol $/ 25 \%$ glacial acetic acid and stained in bulk with the modified Feulgen stain (Schiff reagent, Difco). For each animal the lengths of at least 15 villi and 15 crypts were measured and accumulated metaphases were counted in at least 20 crypts. Villus and crypt lengths are expressed in $\mu \mathrm{m}$ and the crypt cell production rate as the rate of accumulation of metaphases/crypt/hour.

\section{Intraepithelial lymphocyte counts}

Pieces of duodenum were fixed in $10 \%$ buffered formalin, paraffin embedded, cut at $4 \mu \mathrm{m}$, and stained with haematoxylin and eosin. A differential count was made under oil immersion $(\times 1000$ magnification) of the cells within the epithelium covering the villi, and the intraepithelial lymphocyte counts expressed as number of intraepithelial lymphocytes per 100 epithelial cells.

\section{STATISTICS}

Student's $t$ test was used to compare villus and crypt lengths and intraepithelial lymphocyte counts. Crypt cell production rate was calculated from the least squares estimate of the linear regression of number of blocked metaphases with time after colchicine injection. Crypt cell production rates were compared by covariance analysis. The statistical analyses were performed using the SPSS (Statistical package for social sciences) package.

\section{Experiments and results}

EFFECTS OF DIETARY GLUTEN ON UNPRIMED MICE To assess the effect of gluten contained in the diet on the mucosal architecture of our experimental mice, three different sets of observations were made. $B A L B / c$ mice weaned on a normal gluten containing diet or on a gluten free diet were compared seven days after weaning, at the age of 4 weeks; no differences were noted between the two groups in villus and crypt lengths and in crypt cell production rate. In a second experiment adult $\mathrm{BALB} / \mathrm{c}$ mice on a normal gluten containing diet were used, and the effect of seven
Figure 1: Mucosal architecture (left) and intraepithelial lymphocyte (IEL) counts (right) in control and gliadin immunised $B A L B / c$ mice, after seven days of a gluten containing diet. Bars indicate ISD. Six mice per group.

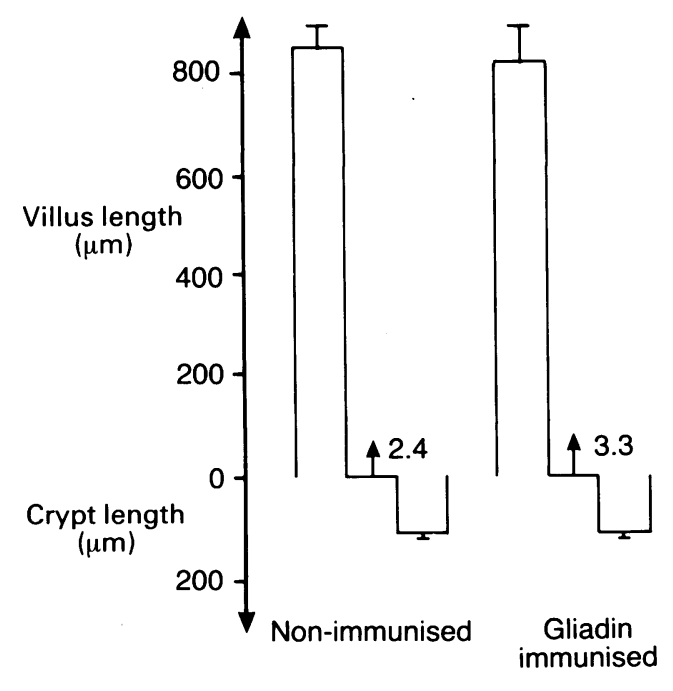




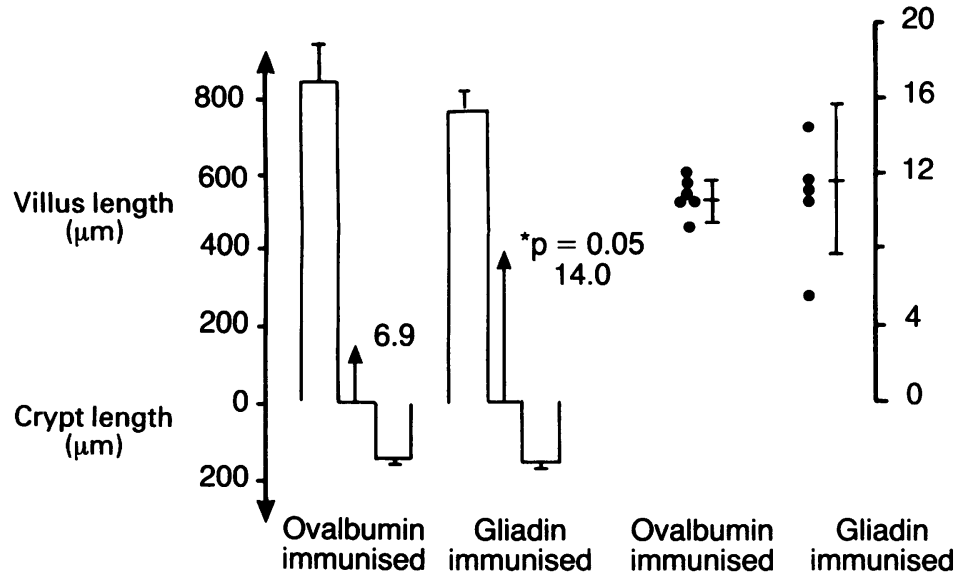

Figure 2: Mucosal architecture (left) and intraepithelial lymphocyte (IEL) counts (right) 12 days after the induction of intestinal anaphylaxis in $B A L B / c$ mice on a gluten containing diet, previously immunised with ovalbumin or with gliadin. Bars indicate 1 SD. Six mice per group.

Figure 3: Mucosal architecture (left) and intraepithelial lymphocyte (IEL) counts (right) 14 days after the induction of graft versus host reaction in $B D F$ mice on a gluten containing diet, previously immunised with ovalbumin or with gliadin. Bars indicate $1 S D$. Five mice in the ovalbumin immunised group, six in the gliadin immunised. days of a gluten free diet on their intestinal architecture was evaluated; again, no change was observed in the parameters studied. Similarly, no differences were noted in adult $\mathrm{BALB} / \mathrm{c}$ mice from a gluten free diet colony transferred for one or seven days to a diet containing gluten. The data are summarised in Table $I$.

\section{Comment}

These results tend to exclude any effect of dietary gluten on the mucosal architecture of normal, unprimed animals, which might have been caused by a lectin like effect of gluten, or by a low grade immune response to an antigen never encountered before.

\section{EFFECTS OF DIETARY GLUTEN ON GLIADIN PRIMED} MICE

With the aim of inducing an intestinal cell mediated immunity reaction to gliadin, BALB/c mice from the gluten free colony were given an intraperitoneal injection of gliadin in complete Freund's adjuvant; control mice were given only the adjuvant. Three weeks later both groups of mice were switched to the standard rodent gluten containing diet and sacrificed after seven days on such a diet. Lengths of villi and crypts, crypt cell production rate, and intraepithelial lymphocyte

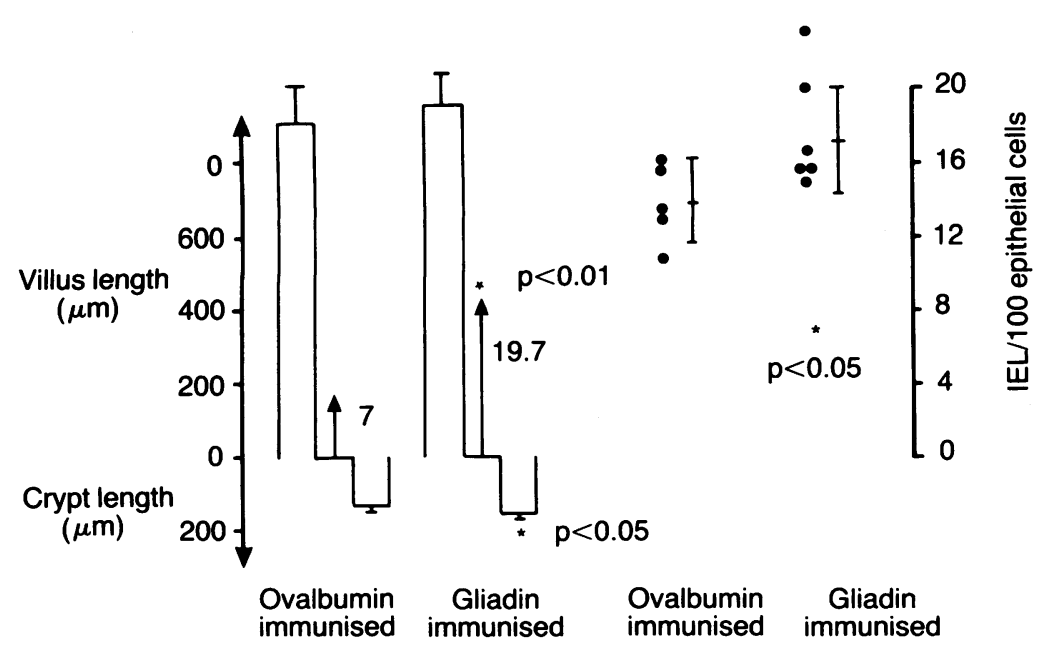

counts were similar in non-immunised and gliadin immunised mice (Fig 1). Similar results were obtained regardless of the route of immunisation-subcutaneous, intrafootpad, or intraperitoneal.

\section{Comment}

The absence of any gluten induced change in the gut architecture of gliadin immunised mice could be explained by a relative lack of specific effector $T$ cells within or recirculating through the gut associated lymphoid tissue. Alternatively, even if sensitised cells are present in abundance, the normal healthy epithelium may not present antigen in such a way as to produce a specific effector response.

\section{EFFECTS OF INTESTINAL ANAPHYLAXIS ON} GLIADIN PRIMED MICE

In a further series of experiments we investigated whether, in addition to the induction of active cell mediated immunity to gliadin, other factors are necessary to allow the expression of a specific mucosal cell mediated immunity response in the gut. In the first of these the effect of intestinal anaphylaxis was evaluated. BALB/c mice were used and maintained throughout on gluten containing diet. They were given an intraperitoneal injection of gliadin in Freund's adjuvant and a boosting injection three weeks later; control animals were immunised with ovalbumin, an unrelated antigen not present in the diet of the mice. At the same time as the booster, both gliadin immunised and ovalbumin immunised animals were infected with Nippostrongylus braziliensis; 10 days later intestinal anaphylaxis was induced by the intravenous injection of Nippostrongylus antigens. Twelve days after anaphylaxis induction mice were sacrificed.

No differences were noted in villus and crypt lengths or in intraepithelial lymphocyte counts between ovalbumin and gliadin immunised mice, but the latter group showed a significantly higher crypt cell production rate (Fig 2). These results support the hypothesis that the specific effector response by gliadin committed cells present in the mucosa is only made possible by changes in the local microenvironment. In this case increased mucosal permeability could play a crucial part by allowing the gliadin present in the diet to come in contact with sensitised cells in the mucosa.

EFFECTS OF GRAFT VERSUS HOST REACTION ON GLIADIN PRIMED MICE

In this experiment the mucosal immune state was modulated by the induction of a graft versus host reaction. $\mathrm{BDF}_{1}$ mice were used, reared and maintained throughout on a gluten containing diet. They were given an intraperitoneal injection of gliadin in Freund's adjuvant and a boosting injection three weeks later. Control animals were immunised with ovalbumin. At the same time as the booster a graft versus host reaction was induced in both groups of mice; groups of animals were then sacrificed 7, 10, and 14 days later. 
TABLE II Duodenal mucosal architecture of $B D F_{1}$ mice on a gluten containing diet, previously parenterally immunised with ovalbumin or gliadin, at 7, 10, and 14 days after the induction of graft versus host reaction (mean $(S D)$, apart from values for crypt cell production rate, which are presented with confidence intervals; 6 mice per group)

\begin{tabular}{|c|c|c|c|}
\hline & $\begin{array}{l}\text { Ovalbumin immunised } \\
(\text { mean }(S D))\end{array}$ & $\begin{array}{l}\text { Gliadin immunised } \\
(\text { mean }(S D))\end{array}$ & $p$ \\
\hline \multicolumn{4}{|l|}{7 days: } \\
\hline Villus length $(\mu \mathrm{m})$ & $793(45)$ & $812(54)$ & NS \\
\hline Crypt length $(\mu \mathrm{m})$ & $132(9)$ & $145(11)$ & $<0.05$ \\
\hline $\begin{array}{l}\text { Crypt cell production rate (mitoses/ } \\
\text { crypt/h) }\end{array}$ & $9.9(7 \cdot 6$ to $12 \cdot 2)$ & $10 \cdot 2(7 \cdot 2$ to $13 \cdot 2)$ & NS \\
\hline $\begin{array}{l}\text { Intraepithelial count (per } 100 \\
\text { enterocytes) } \\
10 \text { days: }\end{array}$ & $10 \cdot 0(2 \cdot 4)$ & $14 \cdot 0(4 \cdot 3)$ & NS \\
\hline Villus length $(\mu \mathrm{m})$ & $830(129)$ & $797(75)$ & NS \\
\hline Crypt length $(\mu \mathrm{m})$ & $133(11)$ & $150(6)$ & $<0.05$ \\
\hline $\begin{array}{l}\text { Crypt cell production rate (mitoses/ } \\
\text { crypt/h) }\end{array}$ & $10 \cdot 4(5 \cdot 7$ to $15 \cdot 1)$ & $11(7 \cdot 6$ to $14 \cdot 4)$ & NS \\
\hline $\begin{array}{l}\text { Intraepithelial count (per } 100 \\
\text { enterocytes) } \\
\text { 14 days: }\end{array}$ & $11 \cdot 2(3 \cdot 4)$ & $13 \cdot 6(3 \cdot 1)$ & NS \\
\hline Villus length $(\mu \mathrm{m})$ & $908(105)$ & $963(121)$ & NS \\
\hline Crypt length $(\mu \mathrm{m})$ & $151(17)$ & $172(10)$ & $<0.05$ \\
\hline $\begin{array}{l}\text { Crypt cell production rate (mitoses/ } \\
\text { crypt/h) }\end{array}$ & $7.0(3.2$ to 10.9$)$ & $19 \cdot 7(13.5$ to 26.0$)$ & $<0.05$ \\
\hline $\begin{array}{l}\text { Intraepithelial count (per } 100 \\
\text { enterocytes) }\end{array}$ & $13 \cdot 9(2 \cdot 2)$ & $17 \cdot 3(2 \cdot 8)$ & $<0.05$ \\
\hline
\end{tabular}

NS $=$ not significant. propria. Similar changes, along with an increase in the proportion of goblet cells, brush border enzyme deficiency, and expression of class II antigens by crypt enterocytes, are features which have been described in allograft rejection, graft versus host reaction, and parasite infection, all of which are characterised by activation of $\mathrm{T}$ cell mediated immunity. ${ }^{9}$ This is the reason why, by analogy with these models, mucosal cell mediated immunity is thought to play a major part in the pathogenesis of the mucosal lesion in coeliac disease. The aim of the experiments described in this paper has been to produce an animal model of gluten associated enteropathy in mice by inducing mucosal cell mediated immunity to gliadin. As there are no standard methods for detecting the presence of antigen specific effector cells in the mucosa, changes in the mucosal architecture have been used as indirect evidence of the presence of mucosal delayed type hypersensitivity.

Gliadin is a protein with peculiar physicochemical properties which make it different from other dietary antigens. In particular, a lectin like activity has been described. ${ }^{10}$ Lectins may produce changes in the brush border membrane, damage to microvilli, and increased exfoliation of absorptive cells, " and so preliminary experiments were necessary to define the effects of gluten on the mucosal architecture of adult unprimed mice. No differences were noted between mice weaned on a normal diet or on a gluten free diet; moreover, the withdrawal of gluten from the diet of mice reared on a normal gluten containing diet, or the introduction of gluten to the diet of mice from the gluten free diet colony, did not produce any changes in mucosal architecture. A lectin like effect of dietary gluten was thus excluded.

As our aim was to produce an intestinal immune response to gliadin, it was first necessary to prime animals by active immunisation. Preliminary attempts to sensitise mice orally were unsuccessful and so we immunised them parenterally. A previous report that systemic priming greatly increases the $\mathrm{T}$ cell immune response in Peyer's patches ${ }^{12}$ supported this approach. Nevertheless, despite the fact that the immunisation scheme used always produces high titres of serum antibody and vigorous cell mediated systemic immunity (assessed by skin tests), no changes were observed in the mucosal architecture of mice systemically immunised with gliadin and then challenged orally with a gluten containing diet. Our data are consistent with a report by Smart et $a l,{ }^{13}$ who failed to produce a mucosal immune response by adoptive transfer of antigliadin monoclonal antibody in mice.

Several factors may account for these negative results. It is conceivable that to obtain a local immune response a critical number of specific $T$ cells is necessary in the mucosa and that they have to escape suppressor influences. It is also possible that in normal conditions accessory cells and factors are not sufficiently abundant in the local microenvironment. Alternatively, the amount of gliadin crossing the epithelium may not normally be sufficient to activate the specifically committed cells within the mucosa.

With the aim of allowing more gliadin to pass
An animal model of gluten sensitive enteropathy should have as its main feature a gliadin induced intestinal mucosal lesion characterised by villus flattening, crypt hyperplasia, and dense infiltration of lymphocytes and other inflammatory cells within the epithelium and lamina 
the epithelial barrier, intestinal anaphylaxis was induced in mice systemically immunised to gliadin. There is increased gut permeability to macromolecules in rodents infected with Nippostrongylus, both during acute infection and when anaphylaxis is induced later by administration of worm antigen. ${ }^{14}$ Under such conditions gliadin immunised mice showed no differences in villus and crypt lengths when compared to controls, but they had a significant increase in crypt epithelial cell production rate.

We then designed an experiment in which we modified even more the local immune state of the gut. This was achieved by inducing a graft versus host reaction in gliadin immunised mice maintained on a gluten containing diet. Test mice in this experiment showed significant differences from ovalbumin immunised control animals in the characteristic markers of cell mediated immunity - crypt length, intraepithelial lymphocyte count, and crypt cell production rate. Specific gliadin associated effects were produced over and above those of the graft versus host reaction. In this case enhanced antigen presentation, ${ }^{15}$ recruitment of specific $T$ cells in the mucosa, upregulation of the expression of class II antigens, ${ }^{16}$ and failure of suppressor mechanisms are all possible mechanisms for the effects observed. We should point out that different immunisation regimens were used for the initial experiments (a single injection) and for the graft versus host and anaphylaxis studies (primary and booster injections). It is extremely unlikely, however, that this could account for the results obtained in the immunomodulation groups; indeed subsequent experiments have shown that the increment in systemic immunity produced by a booster injection is not associated with any cell mediated immune response to gliadin in the gut.

We have not yet produced villus flattening, a hallmark of the histology of coeliac disease. This may be a species specific problem, as in many other experiments we have found mice particularly resistant to villus damage. On the other hand, it is increasingly recognised that there is a continuous spectrum of histological changes in gluten sensitive enteropathy, ranging from an increase in villus intraepithelial lymphocyte count through crypt hypertrophy to the classical picture of a flat coeliac mucosa. ${ }^{1}$ It is possible that greater amounts of dietary gluten in our mice, or prolonging the time of gluten challenge, would lead to further progression of the histological lesion. Experiments along these lines are in progress.

Our experiments show that being primed to gliadin is not a sufficient condition for the development of a $\mathrm{T}$ cell mediated lesion of the intestine. Additional factors, such those occurring during intestinal anaphylaxis or graft versus host reaction, are necessary. These observations support the two stage model of coeliac disease, ${ }^{17}$ which is based on the postulate that 'latent' gluten sensitive enteropathy is a fairly common condition which requires a second insult to allow the evolution of gluten induced intestinal damage and malabsorption. Latent coeliac disese was first reported by Weinstein ${ }^{18}$ and has been shown to occur in patients with dermatitis herpetiformis and in first degree relatives of coeliac patients, some of whom have minor histological abnormalities of the jejunal mucosa while on a normal gluten containing diet. ${ }^{120}$ Analogous to what we have observed in mice, it is conceivable that some coeliac patients have in the first instance altered immunity to gliadin - for example, high titres of serum or secretory antibodies - probably on a genetic basis. Additional non-genetic factors then precipitate the full blown disease, possibly by perturbing the local immune system. Clinically overt coeliac disease is occasionally precipitated by factors such as radical changes in diet, upper gastrointestinal surgery, gastroenteritis, or pregnancy. ${ }^{21}$ The previous state will often have been merely silent, subclinical coeliac disease, but there may be a few patients who are the clinical analogues of our experimental model in whom environmental factors have converted latent disease to fully expressed enteropathy.

We thank Dr H R P Miller and staff, who provided Nippostrongylus larvae and relevant worm antigens, and Mr John Bode for technical assistance. The invaluable work of the staff of the Animal Unit, assistance. The invaluable work of the staff of the Animal Unit,
Western General Hospital, is also gratefully acknowledged. This Western General Hospital, is also gratefully acknowledged. Thi
work was supported by a grant from Fisons Pharmaceuticals.

1 Marsh MN. Studies of intestinal lymphoid tissue. XI. The immunopathology of cell-mediated reactions in gluten sensitivity and other enteropathies. Scanning Microsc 1988; 2: tivity and

2 Mowat A McI. The regulation of immune responses to dietary protein antigens. Immunol Today 1987; 8: 93-8.

3 Troncone R, Ferguson A. Gliadin presented via the gut induces oral tolerance in mice. Clin Exp Immunol 1988; 72 284-7.

4 Simonsen $M$. Graft versus host reaction. Their natural history and applicability as tools of research. Progress in Allerg 1962; 6: 349-476.

5 Clarke RM. Mucosal architecture and epithelial cell production rate in the small intestine of the albino rat. $\mathcal{F}$ Anat 1970 ; 107: 519-29.

6 Tosi $\mathrm{R}$, Vismara D, Tanigaki N, et al. Evidence that celiac disease is primarily associated with a DC locus allelic
specificity. Clin Immunol Immunopathol 1983; 28: 395-404.

7 Batt RM, McLean L. Carter MW. Sequential morphologic and biochemical studies of naturally occurring wheat-sensitive enteropathy in Irish setter dogs. Dig Dis Sci 1987; 32: 184 94.

8 Wagner JD, Jerome CP, Adams MR. Gluten-sensitive enteropathy in a cynomolgus monkey. Lab Anim Sci 1988; 38: 592 4.

9 Ferguson A. Models of immunologically driven small intestinal damage. In: Marsh MN, ed. Immunopathology of the small intestine. Chichester: Wiley, 1987: 225-52.

10 Douglas AP. The binding of a glycopeptide of wheat gluten to intestinal mucosa of normal and coeliac subjects. Clin Chim intestinal mucosa of no $1976 ; 73: 357-61$.

11 Lorenzsson V, Olsen WA. In vivo responses of rat intestina epithelium to intraluminal dietary lectins. Gastroenterology 1982; 82: 838-48.

12 MacDonald TT. Enhancement and suppression of Peyer's patches immune response after systemic priming. Clin $E x$ Immunol 1982; 49: 411-8.

13 Smart CJ, Trejdosiewicz LK, Howdle PD. Anti-gliadin antibodies in the induction of experimental enteropathy. In: McDonald TT, et al. Advances in mucosal immunology. Lancaster, UK: Kluwer Academic: 1990.

14 Ramage JK, Stanisz A, Scicchitano R, Hunt RH, Perdue MH. Effect of immunological reactions on rat intestinal epithelium. Correlation of increased permeability to Chromium 51-labeled ethylenediaminetetraacetic acid and ovalbumin 51-labeled ethylenediaminetetraacetic acid and ovalbumin during acute inflammation

15 Strobel S, Mowat AMcI, Ferguson A. Prevention of ora tolerance induction to ovalbumin and enhanced antigen presentation during a graft-versus-host reaction in mice. Immunology 1985; 56: 57-64.

16 Guy-Grand D, Vassalli P. Gut injury in mouse graft-versushost reaction. Study of its occurrence and mechanisms. fClin Invest 1986; 77: 1584-95.

17 O'Mahony S, Vestey JP, Ferguson A. Similarities in intestinal humoral immunity in Dermatitis Herpetiformis without enteropathy and in coeliac disease. Lancet 1990; 335: 1487 90.

18 Weinstein WM. Latent celiac sprue. Gastroenterology 1974; 66 : 489-93.

19 Doherty $\dot{M}$, Barry RE. Gluten-induced mucosal changes in subjects without overt small bowel disease. Lancet 1981; i 517-20.

20 Ferguson A, Blackwell JN, Barnetson RStC. Effects of additional dietary gluten on the small intestinal mucosa of volunteers and of patients with dermatitis herpetiformis Scand F Gastroenterol 1987; 22: 543-9.

21 Barry RE, Baker P, Read AE. The clinical presentation. Clin Gastroenterol 1974; 3: 55-69. 